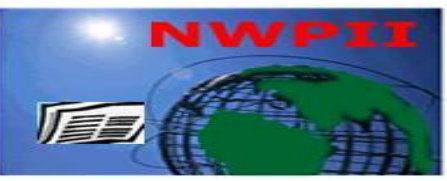

American Journal of Biomedical Sciences

ISSN: 1937-9080

nwpii.com/ajbms

\title{
Atrial Myxoma in Atypical Location: A Case Report
}

\author{
Han $\mathrm{Ni}^{{ }^{*}}$, Aung $\mathrm{Htet}^{2}$, Saw Hla Khaing ${ }^{3}$ \\ ${ }^{1}$ Department of Medicine, Melaka Manipal Medical College, Malaysia \\ ${ }^{2}$ Department of Diagnostic Radiology, Singapore General Hospital, Singapore \\ ${ }^{3}$ Department of Surgery, Melaka Manipal Medical College, Malaysia \\ *Corresponding Author \\ Han $\mathrm{Ni}$ \\ Assistant Professor \\ Department of Medicine \\ Melaka Manipal Medical College \\ Jalan Batu Hampar, Melaka 75150 \\ Malaysia \\ Handphone : + 60168232684 \\ Email : hanni.dr@gmail.com
}

Received:16 May 2012; | Revised: 17 July 2012; | Accepted: 1 August 2012

\begin{abstract}
Introduction: Atrial myxomas are rare cardiac tumours. This case report illustrates a case of myxoma in the right atrium, which is a rare location for this condition.

Case Presentation: A 55 year old Myanmar (Burmese) man had two syncopes within one week. Cardiac evaluation showed changing cardiac murmur. Right atrial enlargement was obvious on electrocardiogram. Transthoracic echocardiogram revealed an echogenic mass in the right atrium which prolapsed through tricuspid valve. The myxoma was successfully excised, the base of which was attached to the interatrial septum at the lower margin of fossa ovalis.

Conclusion: In this case report, we emphasize the uncommon site of myxomas in the right atrium. Clinical suspicion will lead to early diagnosis by echocardiogram and surgical excision is the curative treatment.
\end{abstract}

Keywords: Myxoma, Syncope, Right atrial myxoma

\section{Introduction}

Primary cardiac tumours are rare and found in 0.0017 to 0.19 percent of unselected patients at post mortem [1]. Most primary cardiac tumours are benign, among which myxomas are the most common. Majority of the myxomas occur in the left atrium $(75 \%)$ but there are cases of right atrial myxomas [2]. A case of right atrial myxoma was first reported in 1908 [3].

Majority of the patients with atrial myxoma present with one or more symptoms of clinical triad of embolic events, intracardiac obstruction, or nonspecific manifestations with constitutional symptoms [4]. Myxomas can also be an accidental finding during routine medical checkup of 
asymptomatic healthy people, especially if they are of small size [5].

In this report, we demonstrate a unique case of cardiac myxoma arising from the right atrium presenting with syncopal episodes without features of heart failure or constitutional symptoms which are the more common expected clinical manifestations of right atrial myxomas [6].

\section{Case Report}

A 55 year old man was admitted with two episodes of syncopal attacks within one week. At presentation, his heart rate was 92/ minute, regular and blood pressure was $139 / 90 \mathrm{mmHg}$. He was found to have changing murmurs during daily rounds, with mid diastolic murmur one day and systolic murmur on the other day. An elevated ESR of $70 \mathrm{~mm}$ after first hour was noted on his laboratory data. Other investigative results were normal. His ECG showed sinus rhythm, right axis deviation, $\mathrm{P}$ pulmonale and right ventricular hypertrophy (Figure1). Chest $\mathrm{X}$ ray revealed cardiomegaly (Figure2).

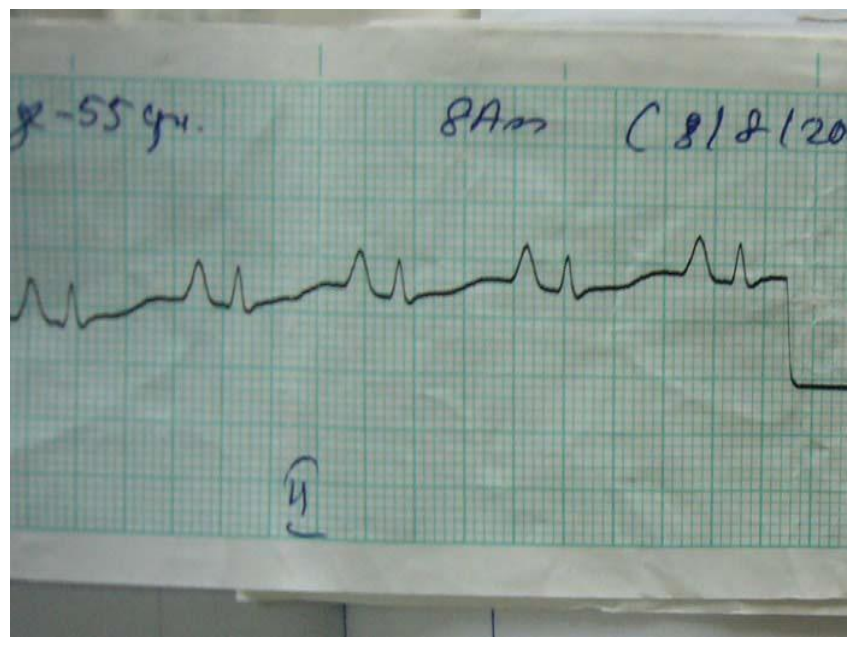

Figure 1. ECG reveals right atrial enlargement (P Pulmonale)

Transthoracic echocardiogram showed normal mitral valve with ejection fraction of 0.56 . There was an echogenic atrial mass of size $4.57 \times 4.41$ $\mathrm{cm}$ in the right atrium, some portion of which prolapsing through and across the tricuspid valve along with mild tricuspid regurgitation (Figure3).

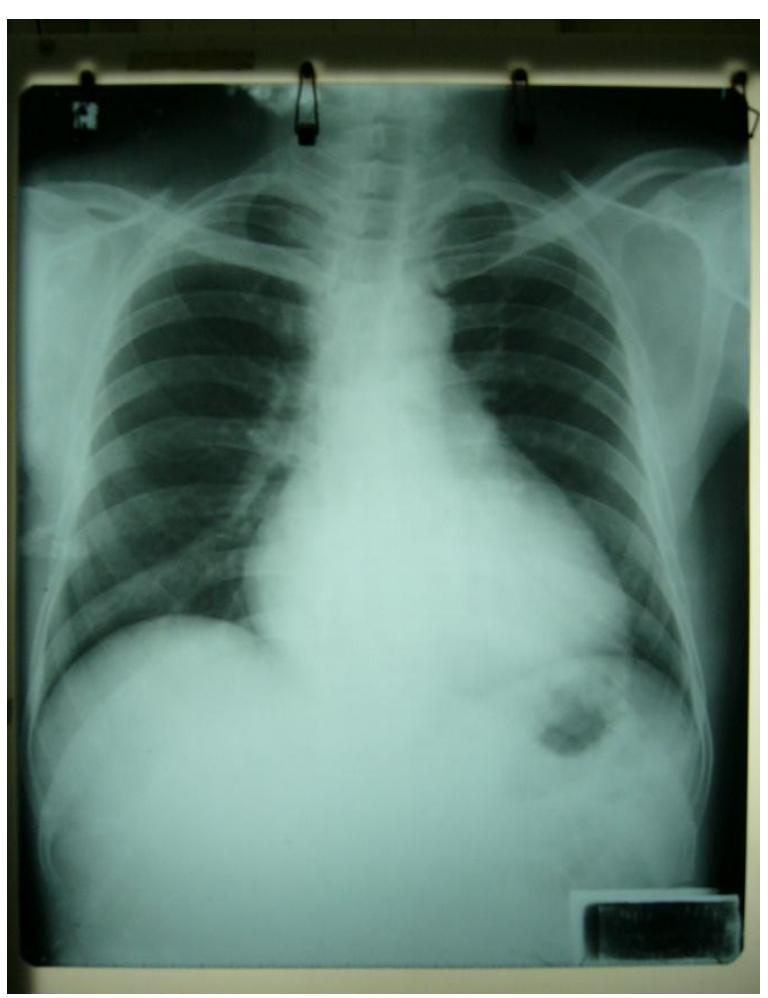

Figure 2. Cardiomegaly without features of heart failure

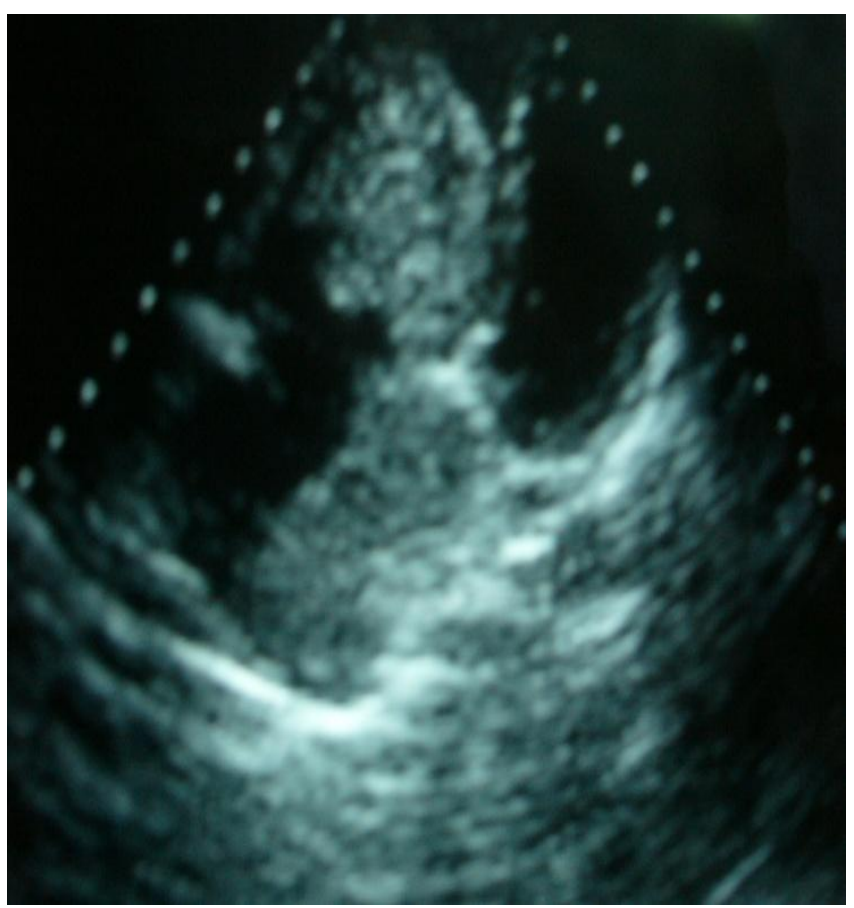

Figure 3. Echocardiogram demonstrates an atrial mass of size $4.57 \times 4.41 \mathrm{~cm}$ in the right atrium with mild tricuspid regurgitation 
He underwent surgical excision under cardiac bypass at cardiovascular surgical unit. Intraoperative findings were hugely dilated right atrium containing jelly like substance of atrial myxoma measuring $6 \times 5 \times 5 \mathrm{~cm}$ in dimension (Figure 4). The pedicle of the myxoma was at the interatrial septum below the lower margin of the Fossa Ovalis. Tumour extension into the inferior vena cava edge was noted but the right ventricle was free of tumour tissue and tricuspid valve was also normal.

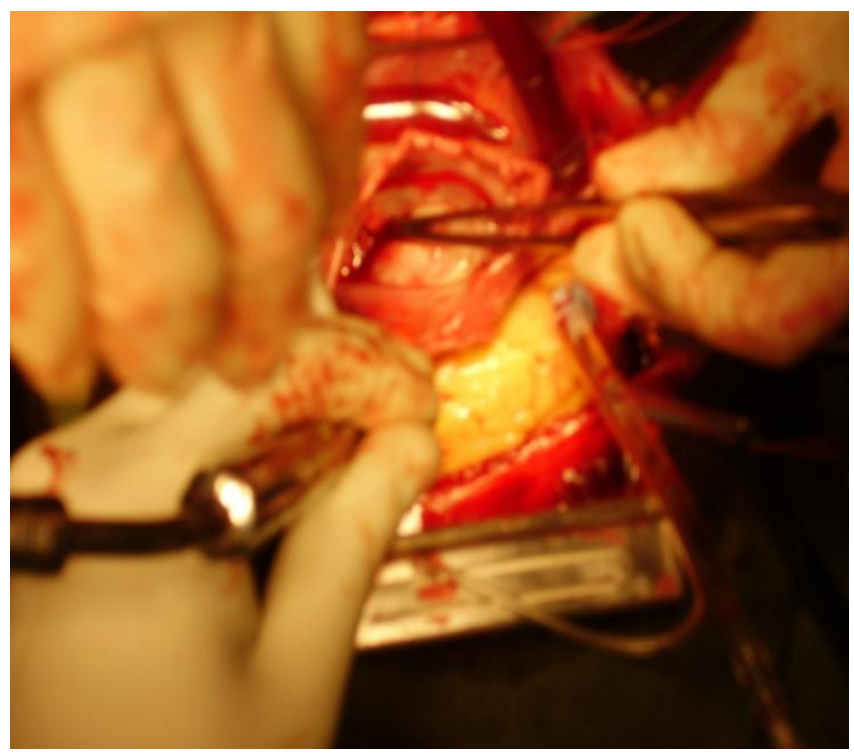

Figure 4. Intra-operative findings of right atrial myxoma

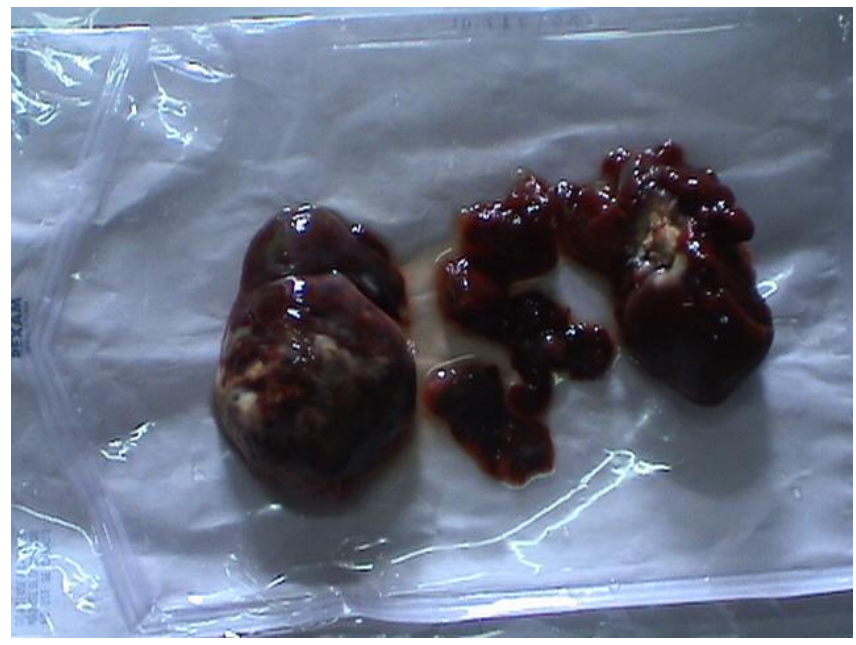

Figure 5. Gelatinous lobulated right atrial myxoma with irregular surface and pieces of loose friable tissue after surgical excision (Main tumour mass with broken pieces due to friability of myxomatous tissue)
Due to the friable nature of myxoma tissue, the tumour was broken into various pieces after surgical excision (Figure 5).

Post operative period was unremarkable and he reported symptomatic improvement on follow up visits.

\section{Discussion}

Primary cardiac tumours are very uncommon, among which $75 \%$ are benign tumours, mostly myxomas [7,8]. The commonest location of cardiac myxomas is in the atrium, mainly the left atrium [9].

Atrial myxomas can be associated with rare inherited syndromes such as Carney complex, which is an autosomal dominant disorder, comprising myxomas (cardiac, skin, bone or breast), skin pigmentations (Lentigenes, Pigmented nevi) and neuroendocrine tumours [10,11]. LAMB (Lentigenes, Atrial myxomas, Mucocutaneous myxomas, and Blue naevi) syndrome and NAME \{Naevi, Atrial myxomas, Myxoid neurofibroma, and Ephelides (freckles) syndrome are subsets of Carney complex [12]. Majority of myxomas occur between $3^{\text {rd }}$ and $6^{\text {th }}$ decades of life [2], as is our case who was 55 years.

The classic features of atrial myxoma are obstruction of blood flow, constitutional symptoms and thromboembolic events. Intracardiac obstruction causes heart failure and syncope. Right atrial myxomas can obstruct tricuspid valve leading to right heart failure, ascites, hepatomegaly, peripheral oedema and syncope [13]. This patient presented with syncope without features of heart failure or constitutional symptoms. Similar cases of right atrial myxomas presenting with syncope have been reported [14, 15].

Constitutional symptoms such as weight loss, fever, elevated erythrocyte sedimentation rate and leucocytosis are seen in atrial myxomas which might be due to release of cytokines [15]. Patients with right sided myxomas are noted to have more systemic symptoms in a retrospective study of 171 cases of atrial myxoma[6]. In this patient, 
erythrocyte sedimentation rate was found to be high but white blood cell count was normal.

Myxomas are friable with high chance of systemic or pulmonary embolization depending on tumour location. In a retrospective study conducted in India, embolism was documented in 9\% of atrial myxomas [6]. Acute cerebral embolism and cerebral aneurysm formation are documented neurological consequences of left atrial myxomas [16]. Other neurological features reported in association with atrial myxomas are multiple cerebral aneurysms and peripheral neuropathy $[16,17]$. Pulmonary embolism is the documented consequence of right atrial myxomas $[18,19]$.

Electrocardiogram will show evidence of chamber enlargement depending on the site of atrial myxoma. In this present case, right atrial enlargement was noted in his ECG, as evidenced by the tall $\mathrm{P}$ wave ( $\mathrm{P}$ pulmonale).

Transthoracic echocardiography is less invasive and has excellent sensitivity in detecting $95 \%$ of myxomas [12]. In this patient, transthoracic echocardiogram detected a right atrial mass which was found to prolapse through tricuspid valve. Similar cases of right atrial myxoma prolapsing through tricuspid valve have been reported. This prolapse is due to the attachment of myxoma on a long stalk [2].

The usual site of attachment of atrial myxoma is the fossa ovalis or base of the interatrial septum as in this case, the pedicle of myxoma was below the lower margin of fossa ovalis at the inter atrial septum. According to a report of 19 years' experience in cardiac surgery of myxomas, 7 cases $(17 \%)$ out of 41 arise from the right atrium, with the mean maximum diameter of $5.1 \pm 1.8 \mathrm{~cm}$ [4]. In our patient, the size of the right atrial myxoma was $6 \times 5 \times 5 \mathrm{~cm}$ in dimension.

Treatment of atrial myxoma is urgent surgical removal in which the pedicle of the mass is resected together with the whole area of attachment [13].

After complete surgical resection of atrial myxomas, there have been reported cases of tumour recurrence. This recurrence is found to be rapid and earlier in familial myxomas associated with Carney complex [10]. Long term follow up of this patient is essential to look for any tumour recurrence.

\section{Conclusion}

Atrial myxomas are rare treatable cause that needs to be excluded in a patient presenting with syncope. Transthoracic echocardiography is an invaluable investigation in the diagnosis of this uncommon condition. Early diagnosis and timely surgical resection is the treatment of choice to prevent possible fatal consequences such as sudden death [7].

\section{References}

1. Reynen, K. Cardiac Myxomas. N Engl J Med, 1995, 333, 1610-1617.

2. Ojji DB, Ajiduku SS, Omonua OO, Abdulkareem LL, Parsonage W. A probable right atrial myxoma prolapsing through the tricuspid valve into the right ventricle: a case report. Cases Journal, 2008, 1, 386. DOI:10.1186/1757-1626-1-386

3. Battellinia R, Bossertb T, Aretaa M, Naviaa D. Successful surgical treatment of a right atrial myxoma complicated by pulmonary embolism. Interactive Cardiovascular and Thoracic Surgery, 2003, 2(4), 555-557. DOI: 10.1016/S1569-9293(03)00133-6

4. St John Sutton MG, Mercier L-A, Giuliani ER, Lie JT. Atrial myxomas: a review of clinical experience in 40 patients. Mayo Clin Proc, 1980, 55, 371-6.

5. M H Tay, K W Lau, Z P Ding, C N Lee. An Interesting Case of Left Atrial Myxoma. Singapore Med J, 2002, 43(7), 367-368.

6. Aggarwal SK, Barik R, Sarma TC, Iyer VR, Sai V, Mishra J. Clinical presentation and investigation findings in cardiac myxomas: new insights from the developing world. Am Heart J, 2007, 154(6), 1102-7. DOI:10.1016/j.ahj.2007.07.032 
7. Ventura F, Landolfa MC, Leoncini A, Gentile R, Gaggero G, Bonsignore A, et al. Sudden death due to primary atrial neoplasms: report of two cases and review of literature. Forensic Sci Int, 2012, 214(1-3), e30-3. http://dx.doi.org/10.1016/j.forsciint.2011.07.0 $\underline{42}$

8. Durgut K, Onoglu R, Gormus N. Primary cardiac myxomas: report of 28 cases and review the literature. $J$ BUON, 2011, 16(2), 345-8.

9. Steger CM, Hager T, Ruttmann E. Primary Cardiac Tumours:A Single-Center 41-Year Experience. ISRN Cardiology vol. 2012, Article ID 906109, 7 pages, 2012. DOI:10.5402/2012/906109

10. Røpcke DM, Bjerre J, Heuck C, van Doorn C. Carney complex: a syndrome with cardial, cutaneous and neuronal tumours. Ugeskr Laeger, 2012, 174(18), 1237-8.

11. Stajevic MS, Vukomanovic VA, Kuburovic VD, Djuricic SM. Early recurrent left atrial myxoma in a teenager with de novo mutation of Carney complex. Indian J Hum Genet, 2011, 17(2), 108-110. DOI: 10.4103/0971$\underline{6866.86200}$

12. Rhodes AR, Silverman RA, Harrist TJ, PerezAtayde AR. Mucocutaneous lentigines, cardio-mucocutaneous myxomas, and multiple blue nevi: The "LAMB" syndrome. $J$ Am Acad Dermatol, 1984, 10(1), 72-82.

13. Nina VJ, Silva NA, Gaspar SF, Rapôso TL, Ferreira EC, Nina RV, et al. Atypical size and location of a right atrial myxoma: a case report. Journal of Medical Case Reports,
2012 Jan 23， 6, 26. DOI:10.1186/17521947-6-26

14. Gogas BD, Rallidis LS, Iliodromitis EK, Kremastinos DT. Right atrial myxoma presenting as syncope due to pulmonary embolism in a previously asymptomatic patient. International Journal of Cardiology, 2011, 148, e34-e36. DOI:10.1016/j.ijcard.2009.02.018

15. Gupta D, Molina E, Palma J, Macha M. Massive right atrial myxoma presenting with syncope. Heart Vessels, 2006, 21(4), 256-7.

16. Baikoussis NG, Siminelakis SN, Kotsanti A, Achenbach K, Argyropoulou M, Goudevenos J. Multiple cerebral mycotic aneurysms due to left atrial myxoma: are there any pitfalls for the cardiac surgeon? Hellenic J Cardiol, 2011, 52(5), 466-8.

17. Hongyi Z, Zhi-Nong W, Liuqing H, Jian H, Danmei L, Zhongxin Z. Atrial myxoma: a rare cause of peripheral neuropathy. Rev Neurol, 2012, 54(3), 188-9.

18. Cheema U, Thomas J. A giant right atrial myxoma presenting as acute pulmonary emboli. Eur Heart J Cardiovasc Imaging, 2012 Apr 18. DOI: 10.1093/ehjci/jes080

19. Subban V, Lakshmanan A, Sethurathinam R, Ajit MS. Right Atrial Myxoma-An Unusual Cause of Pulmonary Embolism. J Card Surg, 2012 Feb 28, DOI:10.1111/j.15408191.2011.01414.x. 